\title{
Retraction Note to: Cascade controller design and stability analysis in FES-aided upper arm stroke rehabilitation robotic system
}

\author{
Wenkang Xu • Chenxiao Cai · Yun Zou
}

Published online: 5 October 2015

(C) Springer Science+Business Media Dordrecht 2015

\section{Retraction Note to: Nonlinear Dyn (2015) \\ 79:1099-1114 \\ DOI: $10.1007 /$ s11071-014-1726-1}

This article has been retracted by the Editor-in-Chief of Nonlinear Dynamics. The stability analysis, which comprises the three-page entirety of Section 4, is an equation-by-equation copy, included without credit or citation, of Section III.C of the paper "Freeman,
Christoper, Tong, Daisy, Meadmore, Katie, Hughes, Ann-Marie, Rogers, Eric and Burridge, Jane (2012) FES based Rehabilitation of the Upper Limb using Input/Output Linearization and ILC. In: 2012 American Control Conference, Montréal, 27-29 June 2012, pp. 4825-4830".

The online version of the original article can be found under doi:10.1007/s11071-014-1726-1.

W. Xu · C. Cai $(\bowtie) \cdot$ Y. Zou

School of Automation, Nanjing University of Science and

Technology, Nanjing 210094, China

e-mail: ccx5281@vip.163.com 